\title{
The Combination of Fosfomycin, Metronidazole, and Recombinant Human Granulocyte-Macrophage Colony-Stimulating Factor is Stable in vitro and Has Maintained Antibacterial Activity
}

\section{Authors}

Siv Fonnes ${ }^{1}$, Barbara Juliane Holzknecht², Lærke Smidt Gasbjerg3, ${ }^{3}$, Johan Juhl Weisser ${ }^{5}$, Hanne Wiese Hallberg², Magnus Arpi², Jacob Rosenberg ${ }^{1}$

\section{Affiliations}

1 Centre for Perioperative Optimisation, Department of Surgery, Herlev and Gentofte Hospital, University of Copenhagen, Herlev, Denmark

2 Department of Clinical Microbiology, Herlev and Gentofte Hospital, University of Copenhagen, Herlev, Denmark

3 Novo Nordisk Foundation Center for Basic Metabolic Research and Department of Biomedical Sciences, Faculty of Health and Medical Sciences, University of Copenhagen, Copenhagen N, Denmark

4 Center for Diabetes Research, Herlev and Gentofte Hospital, University of Copenhagen, Hellerup, Denmark

5 Department of Pharmacy, Faculty of Health and Medical Sciences, University of Copenhagen, Copenhagen $\emptyset$, Denmark

Key words

Antibacterial drugs, inflammation, chemistry

received 13.09.2017

accepted 28.11.2017

Bibliography

DOI https://doi.org/10.1055/s-0043-123933

Published online: 19.12.2017

Drug Res 2018; 68: 349-354

(C) Georg Thieme Verlag KG Stuttgart · New York

ISSN 2194-9379

\section{Correspondence}

Siv Fonnes

Centre for Perioperative Optimisation, Department of

Surgery

Herlev and Gentofte Hospital, University of Copenhagen

Herlev Ringvej 75

DK-2730 Herlev

Denmark

Tel.: + 45/23/21 65 34, Fax: +45/38/68 3772

siv.fonnes@gmail.com

\begin{abstract}
Background Treatment of secondary peritonitis includes surgery and antimicrobial agents. Antimicrobial agents are often administered intravenously, however, the alternative route intraperitoneal administration could be considered. Investigations must be conducted prior to clinical application. Therefore, we aimed to investigate the combination of fosfomycin, metronidazole, and recombinant human granulocyte-macrophage colony-stimulating factor with regard to its chemical properties and the solution's stability. In addition, the antibacterial effect of the mixed drug solution was compared with the effect of the individual antibacterial agents.

Methods The drugs were mixed to an aqueous solution. Basic chemical investigations of $\mathrm{pH}$, precipitation, and calculated osmolarity of the drug combination were conducted. Fosfomycin and metronidazole's chemical stability was investigated using High Pressure Liquid Chromatography-Mass Spectrometry. Microbiological investigations using the agar cup method were carried out to measure the antibacterial effect of fosfomycin and metronidazole.

Results The aqueous solution of the combination of the three drugs had a $\mathrm{pH}$ of 7.46-7.62, which was stable during $24 \mathrm{~h}$, was without precipitation, and had a calculated osmolarity of 293 mOsm/l. High Pressure Liquid Chromatography-Mass Spectrometry found stable concentrations of fosfomycin and metronidazole both alone and in combination during $24 \mathrm{~h}$. The antibacterial effect of the drug combination solution was similar to the antibacterial effects of fosfomycin and metronidazole alone.

Conclusion The drug combination had neutral and stable $\mathrm{pH}$, was iso-osmotic, and had stable concentrations during $24 \mathrm{~h}$ of storage. The antibacterial effect of fosfomycin and metronidazole were not altered when the drugs were mixed.
\end{abstract}




\section{Introduction}

Antimicrobial therapy for intraabdominal infections, either as prophylaxis or treatment, can be administered by different routes. Intravenous administration is the most frequently recommended route of administration [1,2], however, local administration could be superior to systemic administration. This has been employed in e. g. intraperitoneal administration in peritoneal dialysis-associated peritonitis [3].

In peritonitis due to perforation of a hollow organ, which is termed secondary peritonitis, the infection is usually polymicrobial [2]. The recommended treatment is source control [4] together with combination regimens of antimicrobial agents [2]. We propose that combination therapy with fosfomycin, metronidazole, and recombinant human granulocyte-macrophage colony-stimulating factor (rhGM-CSF) administered intraoperatively and intraperitoneally could effectively treat secondary, infectious peritonitis. The drugs have not previously been administered in combination. However, individual administration of each drug intraperitoneally has been reported [5-10]. Fosfomycin (cis-(1 R,2S)-Epoxypropylphosphonic acid [11]) is a phosphonic antibiotic agent [12] with low molecular weight of $138 \mathrm{Da}$ [13]. It enters the bacteria and inhibits the bacterial cell wall synthesis through an irreversible inhibition of the enzyme enolpyruvyl transferase [14]. Therefore, it exhibits bactericidal activity on both Gram-positive and Gram-negative aerobic bacteria in the growth phase. Metronidazole $(1 \mathrm{H}$-Imidazole-1-ethanol, 2-methyl-5-nitro) is a nitroimidazole antimicrobial agent, which has a bactericidal action on anaerobic bacteria and certain protozoa [15]. It has a molecular weight of $171 \mathrm{Da}$ [16]. Its mechanism of action is not fully understood. However, intermediate metabolites of metronidazole are considered cytotoxic and interact with bacterial DNA, which results in destabilisation [15]. The third compound, rhGM-CSF, is a glycoprotein and cytokine that is produced by cells of the immune system such as T lymphocytes, monocytes, fibroblasts, and endothelial cells [17]. The main structure of rhGM-CSF is a four $\alpha$-helix bundle. It works by promoting growth, differentiation, and maturation of macrophages and neutrophil granulocytes and stimulate their activities [17-19]. Thereby, it complements antibiotic treatment by enhancement of the patient's immune response. Previous studies found rhGM-CSF to improve the clinical outcomes of both patients with abdominal sepsis [20] and patients with sepsis admitted to the intensive care unit [21].

Fluids or drugs administered intraperitoneally should preferably be physiological in their constitution prior to clinical application [22]. Therefore, the aim of this study was to investigate the combination of fosfomycin, metronidazole and rhGM-CSF regarding to their chemical properties as an aqueous solution and the antibacterial activity.

\section{Materials and Methods}

\section{Drugs}

The drugs used in this investigation were the following: fosfomycin $2 \mathrm{~g}$ (Infectofos, Infectopharm, Germany) dissolved in sterile water for injections (Sterilt Vand “SAD”, Denmark), metronidazole $5 \mathrm{mg} / \mathrm{ml}$ (Metronidazole “B. Braun”, Denmark), and rhGM-CSF
$0.25 \mu \mathrm{g} / \mu \mathrm{l}$ (Repomol, Reponex Pharmaceuticals, Denmark). We used a total of $4 \mathrm{~g}$ fosfomycin, $1 \mathrm{~g}$ metronidazole, and $50 \mathrm{\mu g}$ rhGMCSF. To optimise the parameters for High Pressure Liquid Chromatography-Mass Spectrometry (HPLC-MS) pure analytical standards were used. These were fosfomycin sodium (Sigma-Aldrich, Glostrup, Denmark) and metronidazole (Sigma-Aldrich, Glostrup, Denmark). We used the internal standards (IS) ethylphophonic acid (Sigma-Aldrich, Glostrup, Denmark) and metronidazole- $\mathrm{d}_{4}$ (Toronto Research Chemicals, ON, Canada).

\section{Basic chemical investigations}

The aims were to determine the $\mathrm{pH}$ of the drugs individually and in combination, and to evaluate if precipitations were present.

A pH-meter (PHM210 Standard pH Meter, Radiometer analytical SAS, Denmark) was calibrated with standard solutions of $\mathrm{pH} 4$ and 10 before use. We dissolved $2 \mathrm{~g}$ fosfomycin in $50 \mathrm{ml}$ water for injections. This step was repeated. We measured $\mathrm{pH}$ and collected photographic documentation. The two fosfomycin solutions were then mixed and $200 \mathrm{ml}$ water for injection was added. Hereafter, we measured $\mathrm{pH}$ and collected photographic documentation. $0.2 \mathrm{ml}$ of rhGM-CSF $(50 \mu \mathrm{g})$ was added to the $300 \mathrm{ml}$ of fosfomycin solution and gently mixed. We measured $\mathrm{pH}$ and collected photographic documentation. Lastly, a total of $200 \mathrm{ml}$ metronidazole $5 \mathrm{mg} / \mathrm{ml}(1 \mathrm{~g})$ was gathered and $\mathrm{pH}$ was measured and photographic documentation was collected. This was mixed with the $300.2 \mathrm{ml}$ solution consisting of fosfomycin and rhGM-CSF and gently mixed resulting in $500.2 \mathrm{ml}$ solution. We measured $\mathrm{pH}$ and collected photographic documentation. The abovementioned protocol was conducted in duplicate. The investigations described in the following section were conducted once. We kept $25 \mathrm{ml}$ of the solution at room temperature $\left(20-25^{\circ} \mathrm{C}\right)$. We measured $\mathrm{pH}$ and collected photographic documentation after $30 \mathrm{~min}, 1,2,4$, 8, and $24 \mathrm{~h}$. The remaining portion of the solution was kept at $37^{\circ} \mathrm{C}$ (simulating the body temperature). We measured $\mathrm{pH}$ and collected photographic documentation after $30 \mathrm{~min}, 1,2,4,8$, and $24 \mathrm{~h}$.

The theoretical osmolarity was calculated based on the available information of the drugs used.

\section{Chemical stability}

The aim was to investigate whether the concentration of fosfomycin and metronidazole alone and in combination was stable during a time period of $24 \mathrm{~h}$ at $37^{\circ} \mathrm{C}$.

Analytical standards dissolved in methanol were used to optimise and develop the methods for HPLC-MS (AB Sciex Qtrap 4500, CA, USA). For both fosfomycin and metronidazole a Kinetex $2.6 \mathrm{u}$ Biphenyl 100 A, 50×2.1 mm column (Phenomenex, USA) was used. In both methodologies mobile phase A consisted of MilliQ water with $0.1 \%$ formic acid ( $\mathrm{v} / \mathrm{v}$ ) and mobile phase B consisted of acetonitrile with $0.1 \%$ formic acid $(v / v)$. For metronidazole the injection volume was $0.5 \mu \mathrm{l}$, autosampler tray temperature was set to $10^{\circ} \mathrm{C}$, and the column oven was set to $35^{\circ} \mathrm{C}$. A binary 1290 Agilent Infinity System performed a gradient flow at $350 \mu \mathrm{l} / \mathrm{min}$. The gradient elution was maintained at $2 \% \mathrm{~B}$ from $0-1.3 \mathrm{~min}$, and $2-98 \%$ B from 1.3-1.8 min where it was held for 2 min before equilibrating the column again. The retention time was $2.15 \mathrm{~min}$ and the total method was $7.5 \mathrm{~min}$ long. Metronidazole was analysed in positive mode where source parameters were set to curtain gas (40 I/min), 
collision gas (medium), ionspray voltage (5000 V), temperature $\left(400^{\circ} \mathrm{C}\right)$, ion source gas $1(30 \mathrm{l} / \mathrm{min})$, and $2(30 \mathrm{l} / \mathrm{min})$. The Q1 parent ion and Q2 daughter ions were 172.0, 128.0, and $110.9 \mathrm{~m} / \mathrm{z}$, respectively. For both $128.0 \mathrm{~m} / \mathrm{z}$ and $110.9 \mathrm{~m} / \mathrm{z}$ the compound parameters were set to declustering potential $(60 \mathrm{~V})$, entrance potential $(10 \mathrm{~V})$, collision energy $(40 \mathrm{~V})$, cell exit potential $(11 \mathrm{~V})$, and the dwell time was 50 msec. For fosfomycin an isocratic method was applied with $10 \% \mathrm{~B}$ with a flow of $300 \mu \mathrm{l}$. The injection volume was $0.1 \mu \mathrm{l}$, tray temperature $8{ }^{\circ} \mathrm{C}$ and the column oven was $30^{\circ} \mathrm{C}$. The retention time was $0.49 \mathrm{~min}$ and the total method was $1.5 \mathrm{~min}$ long. Fosfomycin was analysed in negative mode where source parameters were set to curtain gas ( $40 \mathrm{l} / \mathrm{min})$, collision gas (medium), ionspray voltage $(-4500 \mathrm{~V})$, temperature $\left(450^{\circ} \mathrm{C}\right)$, ion source gas 1 (30 l/min), and $2(30 \mathrm{l} / \mathrm{min})$. The Q1 parent ion and Q2 daughter ions were $136.5,78.7$, and $62.8 \mathrm{~m} / \mathrm{z}$, respectively. For both $78.7 \mathrm{~m} / \mathrm{z}$ and $62.8 \mathrm{~m} / \mathrm{z}$ the compound parameters were set to declustering potential $(-60 \mathrm{~V})$, entrance potential $(-6 \mathrm{~V})$, and the dwell time was $150 \mathrm{~ms}$. Furthermore, the collision energy (-33 V and $-18 \mathrm{~V})$ and cell exit potential (-7V and $-6 \mathrm{~V}$ ) were $78.7 \mathrm{~m} / \mathrm{z}$ and $62.8 \mathrm{~m} / \mathrm{z}$, respectively. Linearity and injection variation was tested within the working range: fosfomycin $2-10 \mathrm{mg} / \mathrm{ml}$ and metronidazole $0.95-$ $2.25 \mathrm{mg} / \mathrm{ml}$. The chemical stability experiment was conducted by four different prepared solutions at $20^{\circ} \mathrm{C}$ : fosfomycin $8 \mathrm{mg} / \mathrm{ml}$ alone, metronidazole $2 \mathrm{mg} / \mathrm{ml}$ alone, rhGM-CSF $1^{*} 10^{-4} \mathrm{mg} / \mathrm{ml}$ alone, and combination; fosfomycin $8 \mathrm{mg} / \mathrm{ml}$, metronidazole $2 \mathrm{mg} /$ $\mathrm{ml}$, and rhGM-CSF $1^{*} 10^{-4} \mathrm{mg} / \mathrm{ml}$. After preparation, all solutions were placed in a dark room at $37{ }^{\circ} \mathrm{C}$. Hereafter, samples of $100 \mu \mathrm{l}$ were collected at $0,1 / 2,1,2,4,8$, and $24 \mathrm{~h}$ and immediately frozen to $-80^{\circ} \mathrm{C}$ where they were kept until analysis. When samples were thawed for analysis $50 \mu \mathrm{l} \mathrm{IS}(10 \mathrm{ng} / \mu \mathrm{l})$ was added, then diluted with $850 \mu \mathrm{l}$ MilliQ water and transferred to $1.5 \mathrm{ml}$ LC vials. All samples were collected in triplicates and data were processed in MultiQuant 3.0 (AB Sciex, CA, USA). Peak areas at time zero was defined as $2 \mathrm{mg} / \mathrm{ml}$ and $8 \mathrm{mg} / \mathrm{ml}$ for metronidazole and fosfomycin, respectively. The concentration in the following time series was determined by comparing the peak area with time zero. Thus, we compared if fosfomycin or metronidazole in either of the setups (alone or in combination) differed significantly during the $24 \mathrm{~h}$.

\section{Microbiological in vitro investigations}

We investigated the antibacterial effect with the agar cup method, which is a diffusion based method to investigate antimicrobial activity [23,24]. The agar cup is a cylindrical hole that is punched into an agar plate, which has been pre-inoculated with a microorganism. A fluid containing the tested agent is pipetted into the hole and the agar plate incubated. The growth inhibition zone correlates with the antimicrobial activity of the substance tested.

The antibacterial effect of fosfomycin was investigated with the bacteria strains Escherichia coli ATCC 25922 and Enterococcus faecalis ATCC 29212 on Mueller-Hinton agar plates (Oxoid, Thermo Fisher Scientific Inc., Denmark) supplemented with $25 \mu \mathrm{g} / \mathrm{ml}$ glucose6-phosphate (Sigma Aldrich, Brøndby, Denmark) under aerobic conditions. The antibacterial effect of metronidazole was investigated with Bacteroides fragilis ATCC 25285 and Bacteroides thetaiotaomicron ATCC 29741 on Brucella Agar plates (Becton Dickinson, Heidelberg, Germany) under anaerobic conditions. Plates were in- oculated with the test strain using an automatic plate rotator. For $E$. coli and E. faecalis, an inoculum of $0.5 \mathrm{McF}$. for $B$. fragilis and $B$. thetaiotaomicron an inoculum of 1 McFarland was used. Then, the plates were dried and two cylinders were punched into each agar plate. One of the holes was filled with a solution of the investigated drug alone in sterile water ("control solution" containing either $200 \mu \mathrm{g}$ fosfomycin or $5 \mu \mathrm{g}$ metronidazole) and the other hole was filled with the combination of the drugs ("combination solution"). For fosfomycin, $200 \mu \mathrm{g}$ in a volume of $40 \mu \mathrm{l}$ was pipetted in a $4 \mathrm{~mm}$ diameter agar cup and for metronidazole, $5 \mu \mathrm{g}$ in a volume of $18 \mu \mathrm{l}$ were pipetted in a $3 \mathrm{~mm}$ agar cup. In the control solution, the same amount of the investigated drug was used and the other two drugs were added. All plates were prepared as quintuples, which resulted in 20 plates in total. The plates with $E$. coli and $E$. faecalis were incubated overnight in ambient air at $35^{\circ} \mathrm{C}(19 \mathrm{~h}$ and $19 \mathrm{~min})$. The plates with $B$. fragilis and $B$. thetaiotaomicron were incubated overnight in an anaerobic chamber at $35^{\circ} \mathrm{C}(18 \mathrm{~h}$ and $54 \mathrm{~min})$.

Inhibition zone diameters were read at the point of complete inhibition as judged by the naked eye by an experienced biomedical laboratory scientist with the plate held around $30 \mathrm{~cm}$ from the eye. Isolated colonies (seen with E.coli) within the inhibition zone were ignored. A negative control without the active agent had been performed in a pilot trial and showed that there was no inhibition of growth.

\section{Statistical methods}

For the investigations of chemical stability with HPLC-MS, it was tested if peak area in time zero was significantly different from time $24 \mathrm{~h}$ using unpaired t-test. For the microbiological investigations the inhibition zone diameters of the two solutions ("combination solution" and "control solution") were compared. As data was not normally distributed, the median of the two solutions' diameter was calculated due to the distribution of data. Inter-test variability was evaluated with a Mann-Whitney-U-test of the diameters due to the distribution of data. A p-value $<0.05$ was considered statistically significant.

\section{Results}

The basic investigations showed that the combination of fosfomycin, metronidazole, and rhGM-CSF resulted in a neutral $\mathrm{pH}$ of 7.467.62 ( $\triangleright$ Table 1$)$. The $\mathrm{pH}$ remained stable at both room temperature and $37^{\circ} \mathrm{C}$ during $24 \mathrm{~h}$ ( $\triangleright$ Fig. 1). Furthermore, no precipitation was present at any stage of the combination of drugs ( $\triangleright$ Table 1 ). The osmolarity was theoretically calculated to $293 \mathrm{mOsm} / \mathrm{l}$.

The HPLC-MS investigations found a stable concentration of both fosfomycin and metronidazole over time ( $>$ Fig. 2). There was no difference at $24 \mathrm{~h}$ between the measured concentration of the drugs alone or in combination for neither fosfomycin $(p=0.5)$ nor metronidazole $(p=0.9)$.

The results of the microbiological in vitro investigations are presented in > Fig. 3. A low intra-test variability was found with a range of $\pm 1 \mathrm{~mm}$ from median for each series. The medians of the inhibition zones were similar for the "combination solution" and the "control solution" in all the bacteria strains ( Fig. 3 ). 
- Table 1 An overview of the drug content in the different solutions including the concentrations, the $\mathrm{pH}$, and an evaluation of precipitations at room temperature. rhGM-CSF: recombinant human granulocyte-macrophage colony-stimulating factor.

\begin{tabular}{|c|c|c|c|c|}
\hline \multicolumn{2}{|c|}{ Drug content and concentration, } & \multirow{2}{*}{$\begin{array}{c}\text { Precipita- } \\
\text { mg/ml }\end{array}$} & pH \\
\cline { 1 - 2 } Fosfomycin & rhGM-CSF & $\begin{array}{r}\text { Metroni- } \\
\text { dazole }\end{array}$ & No & $7.95-7.99$ \\
\hline 40 & & & No & $7.84-7.90$ \\
\hline 13 & & & No & $7.32-7.39$ \\
\hline & 0.25 & & No & $5.04-5.17$ \\
\hline 13 & $1.7^{*} 10^{-4}$ & & No & $7.84-8.01$ \\
\hline 8.0 & $1.0^{*} 10^{-4}$ & 2.0 & No & $7.46-7.62$ \\
\hline
\end{tabular}

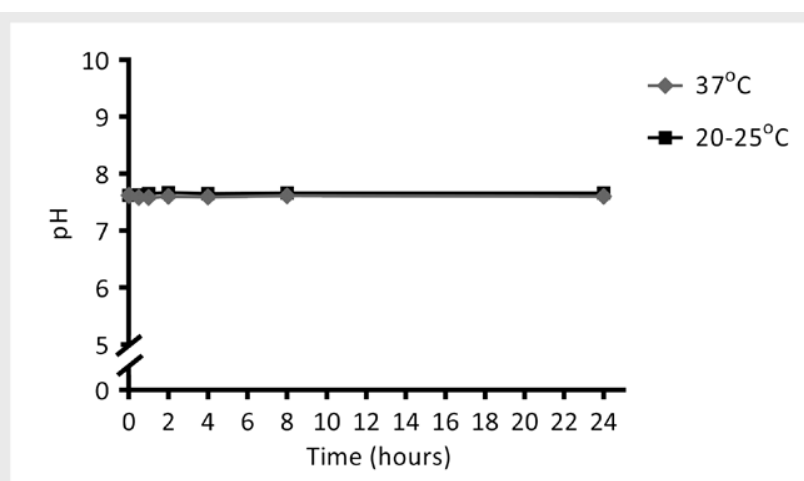

Fig. 1 The $\mathrm{pH}$ of the drug combination of fosfomycin, metronidazole and recombinant human granulocyte-macrophage colonystimulating factor drugs kept at $20-25^{\circ} \mathrm{C}$ (black squares), and $37^{\circ} \mathrm{C}$ (grey diamonds) over a time period of $24 \mathrm{~h}$.

\section{Discussion}

This investigation found that the combination of fosfomycin, rhGM-CSF, and metronidazole had a neutral $\mathrm{pH}$ and was without precipitation. The concentrations of both fosfomycin and metronidazole measured by HPLC-MS were stable during $24 \mathrm{~h}$. Finally, the investigation of the in vitro antibacterial activity by the agar cup method showed that the antibacterial effect of fosfomycin and metronidazole was maintained in the drug combination.

Precipitation has previously been reported for the combination of GM-CSF and other drugs [25]. Sagramostim, which is GM-CSF produced in yeast, was found visually incompatible with antibiotic agents such as ampicillin and ceftazidime. However, visual compatibility was found for sagramostim and metronidazole. We also found rhGM-CSF to be visually compatible when mixed with fosfomycin and metronidazole, thus the drugs can be mixed.

We found that the drug combination had a neutral $\mathrm{pH}$. A neutral $\mathrm{pH}$ is of importance, when administrating drugs intraperitoneally. Low $\mathrm{pH}$ of 5 caused discomfort at administration in peritoneal dialysis [26], and discomfort diminished when the $\mathrm{pH}$ was neutralised $[22,27,28]$. Low pH of the early dialysis fluids has been suspected to cause chronic alterations of the mesothelium of the peritoneal membrane [29]. These alterations were not present when using biocompatible fluids with neutral $\mathrm{pH}[30,31]$. There-

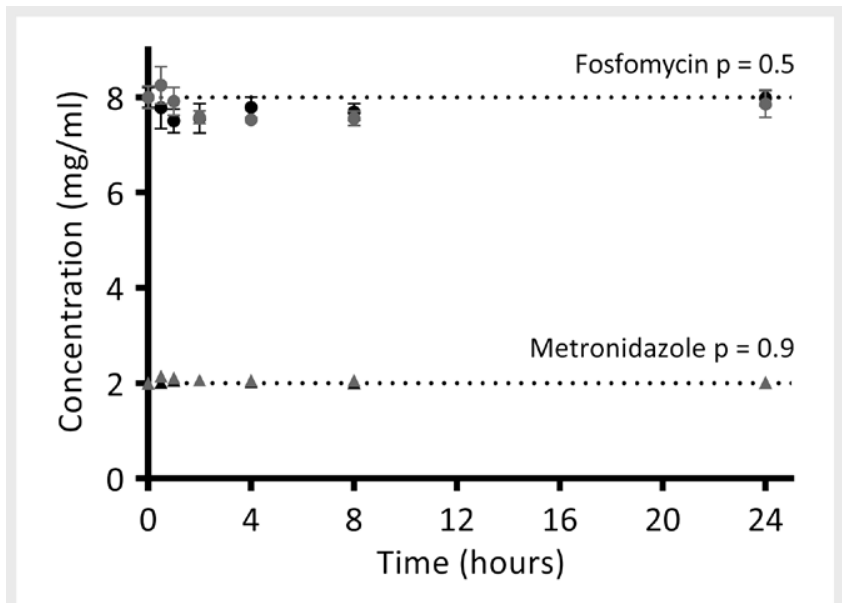

- Fig. 2 Concentrations of fosfomycin (dots) and metronidazole (triangles) alone (grey) and mixed (black) at $37^{\circ} \mathrm{C}$ during a time period of $24 \mathrm{~h}$ measured with High Liquid Chromatography-Mass Spectrometry. The dotted line represents the baseline concentration of each drug. p: $p$-value.

fore, the $\mathrm{pH}$ of 7.46-7.62 found in this investigation is not expected to cause neither discomfort for the patient nor alterations of the peritoneal membrane when the drug combination is administered intraperitoneally.

The in vitro inhibitory effect of fosfomycin on aerobic bacteria and metronidazole on anaerobic bacteria was maintained after the drugs were mixed. This is the first investigation on the antibacterial activity of the drug combination. However, previous studies confirmed the preserved antibacterial activity and stability of fosfomycin in different peritoneal dialysis fluids with bioassays [32,33]. Furthermore, our HPLC-MS analysis confirmed that degradation was neither present for the drugs alone nor in the drug combination solutions during $24 \mathrm{~h}$. Previously, only an unchanged concentration of fosfomycin after mixture with four different peritoneal fluids has been confirmed with HPLC-MS analysis [32].

The strength of these investigations was that all outcomes were predefined in a study protocol, and intra-test variability of the agar cup method was assessed by quintuples to validate interpretation of the test. However, there are some limitations. We do not know the exact limit of detection of the comparative analysis of the antibacterial effect. Since, the results were unambiguous and antagonism of these two drug classes is not expected, we believe that this investigation is adequate to ensure preserved antibacterial activity when the drugs are mixed. Furthermore, in vitro studies cannot predict the exact response in vivo.

In conclusion, we found that the drug combination of fosfomycin, metronidazole and rhGM-CSF in a specific solution could be mixed without precipitation, had neutral $\mathrm{pH}$, and was iso-osmotic. The concentrations of fosfomycin and metronidazol did not change during $24 \mathrm{~h}$, and the antibacterial activity of the two antibacterial agents was not impaired by their combination.

\section{Acknowledgements}

None. 


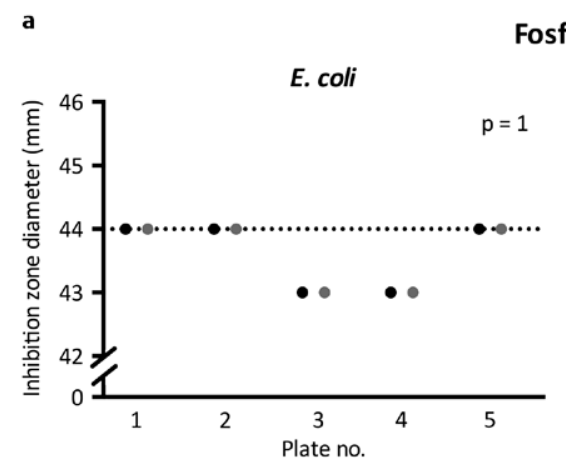

Fosfomycin

b
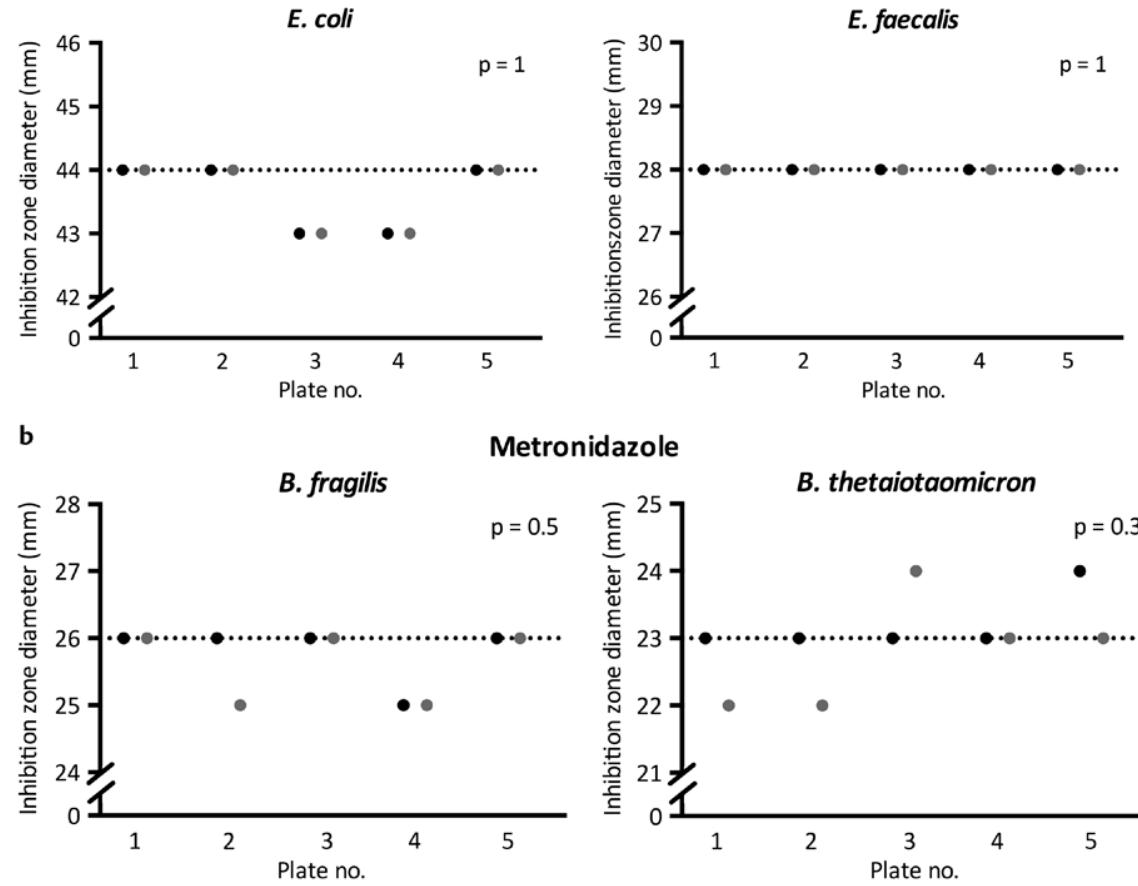

Metronidazole

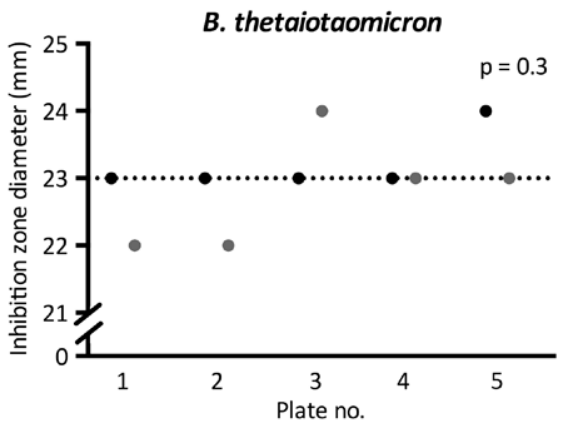

- Fig. 3 Antibacterial effect of fosfomycin (panel A) and metronidazole (panel B). Inhibition zone diameters in millimeters ( $\mathrm{mm}$ ) are shown for "combination solution" (black dots) and the "control solution" (grey dots) of each of the five plates for the four different strains: Escherichia coli, Enterococcus faecalis, Bacteroides fragilis, and Bacteroides thetaiotaomicron. The punctuated line represents the medians, which were identical for the "combination solution" and the "control solution". p: p-value.

\section{Conflict of Interest}

This study was funded by a grant from Reponex Pharmaceuticals ApS to the Department of Surgery, Herlev Hospital. The company did not have any influence on the study design, study conduct, or writing of the manuscript.

\section{References}

[1] O'Neal PB, Itani KMF. Antimicrobial formulation and delivery in the prevention of surgical site infection. Surg Infect (Larchmt) 2016; 17: 275-285

[2] Hasper D, Schefold JC, Baumgart DC. Management of severe abdominal infections. Recent Pat Antiinfect Drug Discov 2009; 4: 57-65

[3] Ballinger AE, Palmer SC, Wiggins K] et al. Treatment for peritoneal dialysis-associated peritonitis. Cochrane Database Syst Rev 2014; 4: CD005284

[4] Malangoni MA, Inui T. Peritonitis - the Western experience. World ] Emerg Surg 2006; 1: 25

[5] Tobudic S, Matzneller P, Stoiser B et al. Pharmacokinetics of intraperitoneal and intravenous fosfomycin in automated peritoneal dialysis patients without peritonitis. Antimicrob Agents Chemother 2012; 56: 3992-3995

[6] Saha SK. Efficacy of metronidazole lavage in treatment of intraperitoneal sepsis. A prospective study. Dig Dis Sci 1996; 41: 1313-1318
[7] Saha SK. Peritoneal lavage with metronidazole. Surg Gynecol Obstet 1985; 160: 335-338

[8] El-Sefi TA, El-Awady HM, Shehata MI et al. Systemic plus local metronidazole and cephazolin in complicated appendicitis: A prospective controlled trial. J R Coll Surg Edinb 1989; 34: 13-16

[9] Selgas R, Fernández de Castro M, Jiménez C et al Immunomodulation of peritoneal macrophages by granulocyte-macrophage colony-stimulating factor in humans. Kidney Int 1996; 50: 2070-2078

[10] Toner GC, Gabrilove JL, Gordon M et al. Phase I trial of intravenous and intraperitoneal administration of granulocyte-macrophage colonystimulating factor. J Immunother Emphasis Tumor Immunol 1994; 15 : 59-66

[11] Drugbank. http://www.drugbank.ca/drugs/DB00828 last accessed 31-08-2017)

[12] Raz R. Fosfomycin: an old-new antibiotic. Clin Microbiol Infect 2012; 18: 4-7

[13] PubChem. https://pubchem.ncbi.nlm.nih.gov/ compound $/ 446987 \#$ section $=2 \mathrm{D}$-Structure (last accessed 31-082017)

[14] Kahan FM, Kahan JS, Cassidy PJ et al. The mechanism of action of fosfomycin (phosphonomycin). Ann N Y Acad Sci 1974; 235: 364-386

[15] Lamp KC, Freeman CD, Klutman NE et al. Pharmacokinetics and pharmacodynamics of the nitroimidazole antimicrobials. Clin Pharmacokinet 1999; 36: 353-373

[16] Drugbank. http://www.drugbank.ca/drugs/DB00916 (last accessed 31-08-2017)

[17] Liles WC, Van Voorhis WC. Review: Nomenclature and biologic significance of cytokines involved in inflammation and the host immune response. J Infect Dis 1995; 172: 1573-1580 
[18] Lieschke G], Burgess AW. Granulocyte colony-stimulating factor and granulocyte-macrophage colony-stimulating factor (1). N Engl J Med 1992; 327: 28-35

[19] Weisbart RH, Gasson JC, Golde DW. Physiology of granulocyte and macrophage colony-stimulating factors in host defense. Hematol Oncol Clin North Am 1989; 3: 401-409

[20] Orozco H, Arch J, Medina-Franco H et al. Molgramostim (GM-CSF) associated with antibiotic treatment in nontraumatic abdominal sepsis: A randomized, double-blind, placebo-controlled clinical trial. Arch Surg 2006; 141: 150-154

[21] Presneill ]J, Harris T, Stewart AG et al. A randomized phase II trial of granulocyte-macrophage colony-stimulating factor therapy in severe sepsis with respiratory dysfunction. Am J Respir Crit Care Med 2002; 166: $138-143$

[22] Yamamoto T, Sakakura T, Yamakawa M et al. Clinical effects of long-term use of neutralized dialysate for continuous ambulatory peritoneal dialysis. Nephron 1992; 60: 324-329

[23] Rose SB, Miller RE. Studies with the agar cup-plate method: I. A standardized agar cup-plate technique. J Bacteriol 1939; 38: 525-537

[24] Bang J. Zone formation in the agar-cup method for determining resistance to antibiotics. Acta Pathol Microbiol Scand Suppl 1956; 39: 192-193

[25] Trissel LA, Bready BB, Kwan JW et al. Visual compatibility of sargramostim with selected antineoplastic agents, anti-infectives, or other drugs during simulated Y-site injection. Am J Hosp Pharm 1992; 49: 402-406
[26] Prakash J, Tripathi K, Singh M. Complications of intermittent peritoneal dialysis. J Assoc Physicians India 1990; 38: 906-908

[27] Rippe B, Simonsen O, Wieslander A et al. Clinical and physiological effects of a new, less toxic and less acidic fluid for peritoneal dialysis. Perit Dial Int 1997; 17: 27-34

[28] Mactier RA, Sprosen TS, Gokal R et al. Bicarbonate and bicarbonate/ lactate peritoneal dialysis solutions for the treatment of infusion pain. Kidney Int 1998; 53: 1061-1067

[29] Williams JD, Craig KJ, Topley N et al. Morphologic changes in the peritoneal membrane of patients with renal disease. J Am Soc Nephrol 2002; 13: 470-479

[30] Williams JD, Topley N, Craig KJ et al. The Euro-Balance Trial: the effect of a new biocompatible peritoneal dialysis fluid (balance) on the peritoneal membrane. Kidney Int 2004; 66: 408-418

[31] Ayuzawa N, Ishibashi Y, Takazawa Y et al. Peritoneal morphology after long-term peritoneal dialysis with biocompatible fluid: Recent clinical practice in Japan. Perit Dial Int 2012; 32: 159-167

Kussmann M, Baumann A, Hauer $S$ et al. Compatibility of fosfomycin with different commercial peritoneal dialysis solutions. Eur J Clin Microbiol Infect Dis. 2017; 36: 2237-2242

[32] Quentin C, Bouchet J], Gaillard I et al. Stability of fosfomycin and quinolones in peritoneal dialysis solution. J Antimicrob Chemother 1990; 25: 878-880 